\title{
LA JURISDICCIÓN CONSTITUCIONAL EN FRANCIA, DE LA APARENTE EXCEPCIÓN EUROPEA AL FIN DE LA SINGULARIDAD FRANCESA
}

\author{
THE CONSTITUTIONAL JURISDICTION IN FRANCE, FROM THE \\ APPARENT EUROPEAN EXCEPTION TO THE END OF THE FRENCH \\ EXCEPTIONALITY
}

\author{
Juan Pablo Sarmiento E.*
}

\begin{abstract}
RESUMEN: El presente documento realiza una descripción de la jurisdicción constitucional francesa y la transformación que puede significar la "cuestión prioritaria de constitucionalidad" para la experiencia gala. Con este trabajo se argumenta que en primer lugar, la práctica francesa había incorporado prácticas comunes en el constitucionalismo europeo, como las "reservas de constitucionalidad". Segundo, se argumenta que la singularidad del control de constitucionalidad francés se ha diluido en la generalidad de la tradición constitucional presente en los Estados europeos occidentales liberales.
\end{abstract}

Palabras clave: Cuestión prioritaria de constitucionalidad, control de constitucionalidad en Francia, modulación de sentencias.

ABSTRACT: This document describes the judicial review in France and the transformation that can mean the "priority question of constitutionality" to the French experience. This paper argues in first place, the French practice has incorporated the common practice in the European constitutionalism, such as "reserves of constitutionality". Second, I argued that the uniqueness of French control constitutionality has been incorporated in the generality constitutional tradition in liberal western European states.

Key words: Priority question of constitutionality, judicial review in France, modulation of sentences.

\section{INTRODUCCIÓN}

El concepto de jurisdicción constitucional que se utiliza en la práctica comprada se emplea en diversos sentidos, solo parcialmente coincidentes. en primer lugar, la jurisdicción constitucional hace referencia a la jurisdicción protectora de los derechos fundamentales. En segundo lugar, se utiliza para describir aquella jurisdicción que puede resolver la constitucionalidad de las leyes. Esta diversidad de usos, opina Rubio Llorente, está justificada por la necesidad de estudiar desde una perspectiva única, instituciones en alguna me-

\footnotetext{
* Abogado de la Pontificia Universidad Javeriana, Magíster y Doctor en Derecho de la Universidad de los Andes. Estancia doctoral en la Universidad de Nantes-Francia. Profesor e investigador de la Universidad del Norte ( $\mathrm{km} 5$ vía puerto Colombia), Barranquilla-Colombia. Este trabajo es resultado de investigación financiado por la Universidad del Norte, sobre precedente judicial, en el Grupo de Investigación de la Universidad. Email: jpsarmiento@uninorte.edu.co, jua-sarm@uniandes.edu.co.
} 
dida diferentes, que tienen su origen último en el hecho de que, en Europa, a diferencia de lo que sucede en los Estados Unidos, jurisdicción constitucional y jurisdicción que aplica la Constitución (constitutional adjudication) no son términos equivalentes ${ }^{1}$.

Los Tribunales Constitucionales han emergido desde mediados del siglo XX como una reacción al ejercicio totalitario del Poder y como medio de control de las mayorías parlamentarias ${ }^{2}$. En su ejercicio institucional, reforzaron el surgimiento del "constitucionalismo", como corriente de pensamiento jurídico que ha dado lugar a la llamada "revolución de los derechos" ${ }^{3}$. Empero, la práctica francesa no parecería haber sido permeable a esta tendencia, en la medida en que la jurisdicción constitucional no tendría cabida en el acuerdo institucional francés, que repudiaba cualquier forma de intervención judicial en las decisiones parlamentarias, aunada a una prolífica y sobresaliente producción en Derecho Administrativo ${ }^{4}$.

Este diseño institucional situó a la experiencia francesa como una excepción al constitucionalismo contemporáneo europeo ${ }^{5}$ y la distanció de otras prácticas como la austriaca, alemana, italiana y española ${ }^{6}$. El arreglo institucional galo es el resultado del temor al "gobierno de los jueces" y la ruptura con el antiguo régimen ${ }^{7}$.

\footnotetext{
1 Rubio (1992) p. 9

2 La experiencia europea ha favorecido y fortalecido notablemente sus órganos de control de constitucionalidad con posterioridad de la segunda guerra mundial, cuando las legislaciones alemana, austriaca e italiana se comprometieron seriamente con la protección de los derechos fundamentales de minorías raciales y étnicas Ginsburg (2006)

3 Sieder (2005)

4 Cappelleti (1990) p. 103

5 El constitucionalismo contemporáneo o neoconstitucionalismo supone cuatro elementos centrales, el primero, la existencia de una jurisdicción constitucional, especializada e independiente; segundo, una labor de control de constitucionalidad fuerte, que permita la exclusión de normas legisladas por su incompatibilidad con la Carta; tercero, el fortalecimiento del precedente, como fuente del derecho, en la medida en que los fallos de los Tribunales constitucionales absorben la labor interpretativa de la Constitución; finalmente, el reconocimiento del poder normativo de los principios, su diferenciación con las reglas, y con ello, el despliegue del poder de los jueces para determinar, provisionalmente, el contenido normativo de dichos principios. EsCOBAR (2006).

6 Cappelleti, (1990) p. 107-109

7 El Código Civil francés dispone en el artículo $5^{\circ}$ la prohibición del "gobierno de los jueces" e impide al juez, por medio de sus fallos, dictar disposiciones generales y reglamentarias sobre las causas que les sean presentadas. Dispone el artículo 50 del Código Civil Francés lo siguiente: "Il est défendu aux juges de prononcer par voie de disposition générale et réglementaire sur les causes qui leur sont soumises". La prohibición expuesta está dirigida contra las "sentencias de reglamento" o "arrêts de règlement", que se refiere a las decisiones de la justicia en las cuales el juez, con ocasión de un litigio, plantea una regla general que aplicará en adelante, a manera de "reglamento". Esta estricta prohibición se encuentra sustentada en la preocupación, ya señalada, de la revolución para contener una muy marcada y definida separación de poderes. Los recursos resueltos para las altas cortes han escapado así de la restricción presente en el artículo 5o del Código Civil francés ya expuesto. Ciertamente, la producción de jurisprudencia por vía de casación se ha reconocido como una fuente de derecho, en tanto poder normativo dentro del ordenamiento jurídico. De igual manera, el Consejo Constitucional Francés ha señalado que su producción jurisprudencial goza de una especial capacidad normativa en cuanto su misma misión lo obliga a pronunciarse por vía general y abstracta. Inclusive, la imposición del artículo $5^{\circ}$ al Consejo desnaturalizaría su función, que si bien no puede entenderse como un poder reglamentario, desarrolla un control normativo de carácter eminentemente vinculante. DiSANT, (2010) p. 235.
} 
No obstante, el Consejo Constitucional francés se desarrolló en medio de una actividad judicial moderada, edificada sobre la aplicación e interpretación de principios generales y de los derechos fundamentales como referentes para el control de constitucionalidad ${ }^{8}$. Lo anterior permitió que la doctrina francesa adoptara una posición más abierta hacia la existencia y funciones de la jurisdicción constitucional. Inclusive, se le ha adjudicado cierta capacidad normativa que se ha hecho cada vez más evidente, en la medida en que el Consejo Constitucional ha articulado en sus decisiones, "reservas de interpretación", y a partir de 2008, la Carta Fundamental fue reformada para ampliar su competencia con la "Cuestión Prioritaria de Constitucionalidad" (en adelante QPC), que convierte al Consejo en una jurisdicción que aplica la Constitución para la protección de derechos y libertades constitucionales.

La QPC tiene la potencialidad de convertirse en un instrumento central para el control de las decisiones de las mayorías parlamentarias. Para desarrollar este argumento, el artículo se dividirá y hará explícita la tensión entre el modelo francés de jurisdicción constitucional (I) y el surgimiento de la jurisdicción constitucional para la protección de derechos y libertades garantizados por la Constitución por medio de la QPC (II).

\section{LA JURISDICCIÓN CONSTITUCIONAL EN EL MODELO FRANCÉS, DE LA APARENTE EXCEPCIÓN FRANCESA AL CONSTITUCIONALISMO CONTEMPORÁNEO}

En la experiencia francesa, la revolución burguesa se mostró hostil hacia el control de las leyes por los tribunales. El término "gobierno de los jueces" ganó sentido peyorativo y se materializó por el Consejo de Estado, quien en varias ocasiones llegó a rechazar el estudio de las leyes y los reglamentos, entendiendo que ambos productos normativos son resultado de dos poderes soberanos, que actúan en el marco de su competencia ${ }^{9}$. Sin embargo, como se probará en este título, la doctrina gala se ha mostrado abierta al ejercicio más activo de la jurisdicción constitucional por medio del reconocimiento del poder normativo de las decisiones de constitucionalidad.

\footnotetext{
8 El derecho de la igualdad y los amplios principios incluidos en el Preámbulo y la Declaración de 1789 son quizá las fuentes de derecho más debatidas. El principio de igualdad, que no es propio ni exclusivo del ordenamiento jurídico francés, ha servido de amplia fuente a la articulación de los demás derechos constitucionales y del preámbulo. Cappelleti (1990) p. 109. Ver entre otras Decisión del Consejo Constitucional 81-132 DC, del 16 de enero de 1982, Gaceta Oficial del 17 de enero de 1982, p. 299. Ver igualmente la Decisión del 20 de diciembre de 1973 del Consejo Constitucional, donde se estudia la Constitucionalidad del artículo 180 del Código Tributario y del artículo 62 de la Ley de Finanzas 1974, a la luz del Derecho a la igualdad, tienden a establecer una discriminación entre los ciudadanos en cuanto a la posibilidad de aportar pruebas en contra de una decisión de la oficina de impuestos sobre la administración, "por lo que esta disposición viola el principio de igualdad ante la ley contenida en la Declaración de los Derechos Humanos de 1789 y formalmente reafirmada por el Preámbulo de la Constitución”.

9 Esta visión no duraría mucho, en tanto el mismo Consejo de Estado extraería del sistema de fuentes del derecho, los "principios", como los derechos del hombre, que abrirían su capacidad de intervención en la interpretación y ampliación del contenido de los reglamentos. CAppelleti, (1990) p. 219 a 221.
} 
La práctica francesa se destaca por contar con un control de constitucional previo, con decisiones que tienen efectos erga omnes. Este diseño institucional supone que el producto legislativo, una vez finalizado y aprobado por el Parlamento, es estudiado automática y previamente por el Consejo Constitucional (artículo 61 de la Constitución francesa de $\left.1958^{10}\right)$. El mismo artículo citado establece como facultativa la solicitud de revisión constitucional que pueden realizar, exclusivamente, el Presidente de la República, el Primer Ministro, el Presidente de la Asamblea Nacional, el Presidente del Senado o sesenta diputados o sesenta senadores. Por su parte, el artículo 62 del texto citado prohíbe al Parlamento y al Ejecutivo, la promulgación y sanción de la ley declarada inconstitucional. En este marco, el sistema franco no contaba con acciones constitucionales dirigidas a facilitar la acción ciudadana directa de control constitucional a posteriori.

Por otra parte, el diseño constitucional francés permite que el Consejo Constitucional pueda declarar que un acuerdo internacional no se encuentra conforme a la Constitución. En ese caso, su ratificación o su aprobación no pueden producirse hasta que se resuelva su revisión de la Constitución. Empero, es necesario tener presente que la intervención del Consejo Constitucional varía según los textos legislativos sobre los que se ejerce el control de constitucionalidad ${ }^{11}$.

Por supuesto, el Control de Constitucionalidad previo comprueba también la regularidad del procedimiento legislativo. Desde 1979 el Consejo Constitucional sostuvo que dentro de sus facultades se encuentra la de examinar si la ley ha sido aprobada dentro del

10 En Francia, el Consejo Constitucional no emerge como consecuencia de la ampliación del dogma de supremacía constitucional o para proteger al ciudadano de los excesos del legislador. Con todo, en su ejercicio institucional, se trasmuta hacia la estabilización de una jurisdicción de contencioso constitucional. Ver Alcoberro, (2011).

11 Meny (1986) p. 135. Siguiendo con la exposición propuesta por Yves Meny, se puede encontrar la siguiente clasificación: a) Las leyes orgánicas, antes de ser promulgadas, y los reglamentos de la Asamblea Nacional y del Senado, antes de ser aplicados, se someten automáticamente al Consejo constitucional. b) Los textos en forma legislativa posteriores al 4 de octubre de 1958 que versan sobre materia reglamentaria son sometidos por el Primer Ministro al Consejo constitucional para que este declare que es posible modificarlos por decreto. c) El desacuerdo entre el Gobierno y la Asamblea parlamentaria sobre la aprobación de una enmienda se somete al Consejo constitucional, sea por solicitud del Primer Ministro o del Presidente de la Asamblea encargada. d) Para apreciar la constitucionalidad de un Acuerdo Internacional, el Consejo solamente puede ser consultado por el Presidente de la República, por el Primer Ministro o por el Presidente de una de las dos Asambleas parlamentarias. e) Las leyes votadas por el Parlamento pueden ser sometidas, antes de ser promulgadas, al Consejo Constitucional por el Presidente de la República, por el Primer Ministro, por el Presidente de la Asamblea Nacional, por el Presidente del Senado, por sesenta diputados o por sesenta senadores. La anterior categorización, en todo caso, no deja de ser problemática. Hay dos categorías que ha suscitado algunos cuestionamientos entre los textos sometidos al control del Consejo: a) Las leyes referendarias. En su decisión del 16 de noviembre de 1962, el Consejo Constitucional, de acuerdo a la solicitud elevada por el presidente del Senado, D. Gastón Monnerville, para pronunciarse sobre el texto de la ley relativa a la elección del presidente de la República por sufragio universal y directo, aprobada por referéndum. En este caso el Consejo se declaró incompetente, señalando que "Las leyes que la Constitución menciona en su artículo 61 son únicamente las leyes votadas por el Parlamento y no las que, aprobadas por el pueblo en referéndum, constituyen la expresión directa de la soberanía nacional”. Esto significa que estas leyes escapan a todo control de constitucionalidad. b) Los textos en forma legislativa. El segundo apartado del artículo 37 de la Constitución autoriza al Gobierno a modificar, por decreto, los textos en forma legislativa que versan -después de la entrada en vigor de la Constitución- sobre el dominio reglamentario, siempre que el Consejo constitucional atribuya a estos textos un carácter reglamentario. 
respeto de las reglas procedimentales para su debate y aprobación, entendiendo que las normas relativas al trámite parlamentario tienen valor constitucional ${ }^{12}$.

Ahora bien, el Consejo Constitucional se ha visto investido de un amplio poder para el control de las leyes objeto de revisión, debido a la amplitud de referentes normativos de superior jerarquía. Justamente, las fuentes del derecho más ricas de la jurisdicción constitucional son el preámbulo de la Constitución de 1958 y el preámbulo de la Constitución de 1946 - que otorgan valor de derecho positivo a la Declaración de los Derechos del Hombre y del Ciudadano de 1789- y los "principios fundamentales de las leyes de la República"13.

La Decisión 44-DC de 1971, supone una profunda transformación al constitucionalismo francés. En efecto, la mencionada decisión del Consejo Constitucional reconoce el poder vinculante y normativo del preámbulo, incorpora los principios fundamentales reconocidos por las leyes de la República y con ello, hace la Constitución pase de tener 92 artículos (en la época) a 125. Así, sería necesario agregar a la Constitución de 1958, los 18 parágrafos del preámbulo de la Constitución de 1946, los 17 artículos de la Declaración de los Derechos del Hombre y del Ciudadano de 1789 y el nuevo principio fundamental reconocido por las leyes de la República, esto es, la libertad de asociación ${ }^{14}$.

Esta decisión, central para el constitucionalismo francés, explica el concepto de "bloque de constitucionalidad", acuñado por Claude Eméri y Jean-Louis Seurin, para integrar "los principios de organización del parlamentarismo limitado"15. De esta manera, el Consejo Constitucional señala que los principios fundamentales reconocidos por las leyes de la República, reafirmados en el preámbulo de la Constitución, amplían el espectro de derechos en la medida en que este cuerpo normativo resulta inseparable de las disposiciones legisladas bajo estudio del Consejo ${ }^{16}$.

12 MenY (1986) p. 140. Señala el autor citado que por medio de la decisión del 24 de diciembre de 1979 (BOE del 26 de diciembre de 1979, página 3259), el Consejo Constitucional declara inconstitucional la totalidad de la ley de presupuestos para 1980 alegando una corrupción del proceso. La Ordenanza orgánica del 2 de enero de 1959 exige que la primera parte de la ley de presupuestos, que autoriza y evalúa los gastos, establezca los topes de las grandes categorías de gastos y determine los datos generales del equilibrio económico y financiero sea votada (y no solamente debatida) antes de que se discuta la segunda parte. Sin embargo, la ley de presupuestos se aprobó después del compromiso de la responsabilidad del Gobierno sobre el conjunto de las dos partes de este texto (artículo 49, apartado 3) sin que las resoluciones de la primera parte y las de la segunda hayan podido ser votadas (o "consideradas como aprobadas» en caso de recurso al artículo 49) de manera distinta y sucesiva como lo exige el artículo 40 de la Ordenanza de 1949.

13 Decisión 44 D.C., 16 juillet 1971, Recueil p. 29 - Liberté d'association L. Favoreu y L. Philip , Les grandes décisions du Conseil constitutionnel, 12a ed., Paris, Dalloz, 2003, pp. 237-255 Decisión núm. 81-132 DC del 16 de enero de 1982 Loi de nationalisation, Considerando 15. ${ }^{\circ}$ Igualmente, cita la Decisión núm. 2008564 DC de 18 de junio de 2004, Loi relative aux OGM. Citados por Alcoberro (2011) p. 25.

14 Dávila (2013) p. 150

15 DÁVila (2013) p. 151

16 La Decisión 44DC del Consejo Constitucional señaló, en su texto original : Considerando que los principios fundamentales reconocidos por las leyes de la República solemnemente son reafirmados en el preámbulo de la Constitución, es necesario disponer el principio de la libertad de asociación; este principio es la base de las disposiciones generales de la Ley de 1 de julio 1901 en contratos de asociación; que en virtud de este principio las asociaciones son gratuitas y pueden hacerse públicos, caso en el cual se sujeta a la presentación de una declaración previa; por lo tanto, con la excepción de las medidas que pueden ser tomadas en relación con categorías específicas de asociaciones, la formación de asociaciones, a pesar de que parece nula o tener un objeto ilícito, no 
La misma tarea de interpretar la ley y su conformidad con la Constitución ${ }^{17}$, permite al Consejo Constitucional extender "reservas" de interpretación. Estas reservas tienen como objetivo precisar el sentido de ciertas disposiciones legislativas y a veces limita su eficacia, para evitar con ello la aplicación de una norma contraria a la Constitución. A pesar de ello, el Ejecutivo es libre de solicitar al Parlamento una nueva lectura de la disposición señalada como inconstitucional ${ }^{18}$.

De esta manera, aunque la doctrina francesa más antigua ha censurado el "gobierno de los jueces", el Consejo Constitucional ha desplegado, en ejercicio del control constitucional abstracto, "reservas" que pueden tener distintos efectos. Se habla de un "poder normativo" del Consejo Constitucional francés en la medida en que, con cada "reserva", aporta o excluye interpretaciones que de alguna manera vayan en contra de la Constitución ${ }^{19}$. Lo señalado supone una diferenciación ideal entre disposición y norma. Disposición se define como "la formulación gramatical o lingüística en la que se expresa un significado normativo"; y norma se entiende como "el significado que se otorga u obtiene al interpretar la disposición”. La relación entre estos dos conceptos no es biunívoca, es decir, no siempre a cada disposición le corresponde una sola norma, ni cada norma es consecuencia de una sola disposición. Así, estas reservas pueden condicionar el contenido normativo de la disposición analizada ${ }^{20}$ o determinar los efectos que en el tiempo puedan tener sus decisiones -esto es, dotar a sus decisiones de efectos retroactivos o efectos hacia futuro- ${ }^{21}$.

Así, por medio de las reservas de interpretación, el Consejo modifica el contenido de la disposición mediante de la supresión de las normas que de esta se deriva. De gran desarrollo en Italia, la función creativa de los tribunales constitucionales es considerada como un estado inevitable en la evolución de la jurisdicción constitucional. En este sentido, el Consejo Constitucional francés acude a las sentencias "normativas o manipulativas" que aparecen como instrumentos procesales necesarios para mantener el "efecto útil" de los actos jurídicos del parlamento, y mediar entre el interés del legislador y la Constitución ${ }^{22}$.

La tarea interpretativa del Consejo Constitucional francés supone entonces un ejercicio normativo importante y no poco utilizado ${ }^{23}$, que nos permite encontrar más similitudes

puede ser presentado para su validez a la intervención previa de la autoridad administrativa o incluso la autoridad judicial (Traducción del autor).

17 Es necesario mencionar que el Consejo Constitucional, en pocas ocasiones, pero enfáticamente, ha señalado que tiene jurisdicción para controlar la interpretación jurisprudencial de disposiciones normativas. Como lo señala la autora Carina Alcoberro, el Consejo ha expuesto que "todo justiciable goza del derecho de cuestionar la constitucionalidad efectiva que una interpretación jurisprudencial constante confiere a tal disposición”, en una decisión jurisprudencial bastante delicada, como lo fue la adopción por las parejas del mismo sexo. AlCOBERRO (2011) p. 34. cita la Decisión núm. 2010-52 QPC, de 14 de octubre de 2010, Compagnie agricole de la Crau, considerando $4^{\circ}$.

18 Lachaire (2002) p. 11.

19 DíAz (2001) p. 37.

20 Escobar (2006) p. 27

21 DisANT (2010) p. 225 a 230

22 Hernández (1994) p. 240

23 Di Manno (1997) p. $339 \mathrm{El}$ autor citado ha estudiado cuantitativamente las decisiones que contienen "reservas de interpretación”, encontrando que, entre 1959 y 1997 el Consejo Constitucional emitió un 34.56\% de 
que diferencias con el resto de la práctica europea. Incluso, se constata que en buena parte de sus decisiones, el mismo Consejo propone las interpretaciones y las normas que contiene la disposición legislativa, para, precisamente, ejercer un control y limitar o ampliar el alcance de la disposición, para así, permitir que la ley entre en vigencia, pero a la vez, garantizar que esta se encuentre acorde con la Constitución ${ }^{24}$.

De esta manera, se ha reconocido que las "reservas" constituyen en realidad un instrumento "pretoriano" construido por el Consejo Constitucional para arrogarse, "discreta, pero eficazmente, un poder de colegislación" 25 . Su legitimidad, al igual que la experiencia comparada alemana, italiana y española se encuentra en entredicho, en la medida en que dichos tribunales toman decisiones que complementan y modifican el contenido normativo de la decisión parlamentaria. Para la experiencia franca, el principal argumento en contra de las "reservas de constitucionalidad" reside en la ausencia de norma expresa que autorice su utilización ${ }^{26}$. Con todo, la interpretación conforme a la Constitución es una herramienta que contribuye a enmendar la ley para que la misma esté de acuerdo y resguarde las disposiciones constitucionales ${ }^{27}$.

Al final de cuentas, las reservas de constitucionalidad se han justificado en el artículo 22 de la ordenanza No. 58-1067 del 7 de noviembre de 1958. Esta norma señala que el Consejo Constitucional ejerce su control facultado, como alta instancia, para declarar no conforme con las disposiciones de la ley, aquellas normas "inseparables" de las disposiciones tachadas de inconstitucionales. De esta forma, el Consejo adquiere una autonomía interpretativa que parece obligarla a mantener la constitucionalidad de la ley, hasta tanto se puedan remover de su contenido aquellas interpretaciones (normas) que sean contrarias al texto fundamental ${ }^{28}$. La expresión "decisiones interpretativas" puede ser calificada legítimamente de "tautológica", si se le considera como el "pasaje obligatorio" que permite a la decisión jurisdiccional cumplir con su función de control de constitucionalidad ${ }^{29}$.

El control de constitucionalidad a priori, parece haber neutralizado los problemas políticos de sus sentencias en cuanto, una vez pronunciada la decisión del Consejo, y previa a su promulgación, las "reservas" planteadas por el Consejo se incorporan al cuerpo norma-

sentencias moduladas, siendo 84 decisiones de 243 emitidas en el período analizado. Esto demuestra que esta práctica judicial no es novedosa ni extraña para la jurisdicción constitucional francesa.

24 Di Manno (1997) p. 45 y 46.

25 Viala (1999) p. 29 y 30.

26 Viala (1999) p. 30.

27 Di Manno (1997) p. 46

28 Di Manno (1997) p. 89. El principio de la "conservación de los actos jurídicos" o de "efecto útil" ha sido usado por la doctrina francesa para explicar la necesidad de mediar, por medio de sentencias interpretativas, entre la voluntad del legislador y la eficacia de la Constitución. El rol del juez constitucional, para este caso, no es el de conservar las leyes sino de conservar la Constitución eliminando las leyes inconstitucionales. No obstante, se observa con frecuencia que no hay una contradicción irremediable en querer conservar las leyes y la constitución, sacrificando algún contenido de las primeras. En la experiencia francesa, este principio se soporta en el artículo 1157 del Código Civil, que dispone "lorsqu’une clause est susceptible de deux sens, on doit plutôt l'entendre dans celui avec lequel elle peut avoir quelque effet, que dans le sens avec lequel elle n'en pourrait produire aucun".

29 Di Manno (1997) p. 47 
tivo $^{30}$. Para algunos autores, el control a priori o ex ante garantizaría ideales de igualdad y seguridad jurídica, pues no permitiría discrepancias entre diferentes jueces e instancias del sistema y la aplicación sería así previsible e igualitaria para todos los ciudadanos ${ }^{31}$. En experiencias donde el control de constitucionalidad es posterior, los Tribunales constitucionales se ven inmersos en decisiones que tienen consecuencias políticas en la medida en que deciden los efectos de normas legisladas que tienen efectos sobre derechos y situaciones jurídicas individuales, algunas veces consolidadas, que refrendan o no decisiones tomadas por mayorías parlamentarias que han ganado eficacia. Por ello, las "reservas" de constitucionalidad en controles de constitucionalidad a posteriori permiten observar que en ocasiones, se produce un enriquecimiento normativo de las disposiciones condicionalmente constitucionales, así como la articulación de oportunidades políticas de los Tribunales constitucionales por medio de las "reservas" 32 .

De igual forma, el Consejo Constitucional, a la luz del "principio de la conservación de los actos jurídicos" o "efecto útil", ha planteado diversas formas de modificar el contenido normativo de las disposiciones por medio de las llamadas "técnicas de interpretación condicional”. La primera de ellas está enmarcada en lo que se puede llamar la anulación "pura y simple" de la ley, que se da normalmente por dos circunstancias, la primera, porque la ley no tiene diferentes normas, que conduce a que el juez constitucional declare inconstitucional toda la ley. La otra circunstancia que se ubica dentro de este tipo de anulaciones es provocada por los vicios de procedimiento en el trámite legislativo ${ }^{33}$.

La segunda técnica de interpretación condicional utilizada por el Consejo Constitucional son las reservas llamadas "neutralizantes negativas" y "condicionamientos positivos". Las primeras se refieren a la supresión de una de las normas presentes en la disposición, donde incluso el cuerpo dispositivo puede quedar intacto, pero suprime alguna de las normas, es decir, una de las interpretaciones posibles de la disposición estudiada. La segunda, la "positiva", se refiere a aquella que supone la adición de alguna norma dentro de la disposición, que incorpora al cuerpo legislativo una interpretación más allá de lo establecido en el cuerpo legal analizado ${ }^{34}$.

Las sentencias interpretativas "integradoras" son aquellas en donde el Consejo Constitucional francés parece menos activo, aunque puede limitar o ampliar en todo caso, el contenido normativo de la disposición. En este tipo de decisiones, el Consejo ha optado, para efectos de mantener la eficacia de la ley y su constitucionalidad, por condicionar

30 Di Manno (1997) p. 133-139.

31 Orunesu (2012) p. 109.

32 SARMiento (2012)

33 Di Manno (1997) p. 133-139. Cita la Decisión No. 83-164 del Consejo Constitucional francés del 29 de diciembre de 1983.

34 Di Manno (1997) p. 251. Se presentan por el autor como "neutralizantes" en la medida en que retiran o agregan normas que contienen las razones de inconstitucionalidad de la disposición, por ello, neutralizan los efectos nocivos de la ley frente a la constitución. De modo similar al inmediatamente expuesto, se habla de una reserva constructiva cuando el Consejo Constitucional enriquece y completa el objeto el contenido normativo de la disposición; por el contrario, la reserva neutralizante reduce un cierto número de elementos constitutivos de la sustancia de la ley estudiada. Viala (1999) p. 75. Cita al Consejo Constitucional, Decisión No. 83-176 del 19 de enero de 1984. 
su interpretación a la lectura sistemática de otras disposiciones también presentes en el ordenamiento jurídico ${ }^{35}$. Las sentencias integradoras no modifican sustancialmente la norma ni la declaran inconstitucional; en efecto, el Consejo integra la norma estudiada con otras normas, legales o constitucionales, para darle a la disposición acusada el alcance que resulta adecuado a la Constitución. En sí mismas no suponen un remedio a situaciones de conflicto con normas superiores, debido a que su interpretación obedece solo a un ejercicio hermenéutico que articula la disposición analizada con otras fuentes del derecho presentes en el sistema jurídico ${ }^{36}$.

Dentro de la tipología de las sentencias interpretativas utilizadas en la jurisdicción constitucional franca encontramos también la "constitucionalidad temporal de una ley" ${ }^{37}$. Este tipo de decisiones judiciales, llamadas de "derecho vivo", se proyectan "apreciando el impacto futuro que tendrá la ley controlada” ${ }^{38}$. El Consejo hace un pronóstico sobre el impacto social y su aplicación futura ${ }^{39}$.

El Consejo Constitucional francés también ha hecho usos de las apelaciones al legislador, también citadas como declaraciones de inoperancia o directivas de interpretación. Esta categoría tiende a señalar que la norma es constitucional, siempre que el legislador desarrolle, en otra ley, un contenido más garantista u oportuno para la Constitución. Estas decisiones de constitucionalidad han privado de eficacia, en la práctica francesa, a una ley, que en principio es "inofensiva", pero que de aplicarse sin la complementación de otra norma, conduciría a una situación inconstitucional, que en algunas oportunidades se dirige incluso al poder reglamentario. En ocasiones, dichas directivas de interpretación se dirigen también de manera tal que obligan a que el legislador, en producciones normativas posteriores, desarrolle ampliamente uno u otro principio, incluso, algún tratado internacional, como es el caso de las "medidas cautelares contra el legislador" (des injonctions à l'égard du législateur) ${ }^{40}$.

Aunque en algunos casos intentan transformar la significación de la ley, producen "manipulaciones", sin alterar la formulación textual de la ley. La inconstitucionalidad se constata en la medida en que el "silencio" de la ley vulnera el derecho a la igualdad de la Declaración de 1789.

\footnotetext{
35 Di Manno (1997) p. 168-173. Cita al Consejo Constitucional, Decisión No. 84-172 del 26 de julio de 1984.

36 SARMiento (2012) p. 307-308.

37 Sarmiento (2010) p. 161-192.

38 Aunque se trata de una práctica rechazada por el propio Consejo Constitucional, el autor Di Manno logra demostrar cómo en varias sentencias el Consejo ha seguido esta práctica. La primera sentencia rastreada sobre el rechazo a un pronunciamiento en este sentido es la Decisión No. 86-207 del 25 y 26 de junio de 1986, donde el tribunal afirmó "l'éventualité d’un détournement de procédure ou d’un abus dans l'application d'une loi ne saurait la faire regarder comme contraire à la Constitution”. Di MANNO (1997) p. 191.

39 Di Manno (1997) p. 191 Cita la Decisión No. 93-329 del 13 de enero de 1994 del Consejo Constitucional. En esa oportunidad el Consejo decidió la constitucionalidad de la reforma a la ley Falloux, que regulaba las modalidades de aplicación de un principio de asistencia a las colectividades públicas diferente a la ofrecida a los establecimientos privados, que resultaba lesivo para el principio de igualdad, siendo inconstitucional no el texto, sino la manera en que sería aplicado.

40 Viala (1999) p. 75 a 80. Cita al Consejo Constitucional, Decisión 82-142 del 27 de julio de 1982.
} 
Las decisiones del Consejo Constitucional francés se han acercado también a las llamadas "sentencias aditivas" de la experiencia italiana. Esta técnica intenta remediar las dificultadas provocadas por la omisión legislativa. Estas omisiones legislativas se pueden clasificar de la siguiente manera: la omisión relativa y la omisión absoluta. La primera se refiere a la regulación incompleta o "defectuosa" de la materia objeto de regulación, que usualmente afecta el derecho a la igualdad; la omisión legislativa absoluta hace referencia a la completa inacción que impide la creación de algún cuerpo normativo ${ }^{41}$. Para la mayoría de asuntos, los tribunales se declaran inhibidos en el caso de la omisión legislativa absoluta, en la medida en que no encuentran ninguna norma que estudiar, y por ello, carecen de objeto en el litigio constitucional en la medida en que no existe ninguna regla sobre la cual pueda recaer el control de constitucionalidad.

En efecto, las omisiones legislativas absolutas han sido excluidas de cualquier examen de constitucionalidad ${ }^{42}$, mientras que las omisiones legislativas relativas han sido controladas por medio de la anulación, evitando las más de las veces, que la disposición completa sea promulgada. Con todo, la decisión No. 86-214 del 3 de septiembre de 1986 parece mostrar otra historia ${ }^{43}$, en especial, en la medida en que adiciona una norma relativa al enjuiciamiento penal que amplía algunas garantías en principio ausentes en el texto normativo $^{44}$.

\section{LA CUESTIÓN PRIORITARIA DE CONSTITUCIONALIDAD, EL SURGIMIENTO DE LA JURISDICCIÓN CONSTITUCIONAL PARA LA PROTECCIÓN DE DERECHOS Y LIBERTADES CONSTITUCIONALES}

La experiencia gala ha abandonado el régimen de excepción aparente que se ha descrito en el título anterior, y ha pasado a formar parte de la tradición constitucional europea a partir de la reforma del año 2008, vigente desde marzo del 2010. En dicha reforma, flore-

41 Sarmiento (2012) p. 288.

42 Di Manno (1997) p. 252. Cita Conseil constitutionnel, rapport français présenté à la VIIe Conférence des Cours Constitutionnelles européenes, Lisbonne, 26-30 avril 1987, in A.I.J.C., III-1987.

43 El considerando No. 4 de la Decisión 86-214 del 03 de septiembre de 1986 contiene el punto expuesto. El Consejo señaló que la acusación contrael artículo 733-1 del Código de Procedimiento Penal, reunió estos requisitos; "De hecho, mientras que da al fiscal la oportunidad para referirse a la Corte criminal que actúa en Salas o, en su caso, ante el Tribunal de Menores, las decisiones del juez de Ejecución de las Penas, el artículo 733-1 especifica que el tribunal no puede tomar su decisión después de 'haber realizado todas las audiencias necesarias y escuchado sus puntos de vista, si así lo solicitan, los consejos de convictos y parte civil'; dichas disposiciones implican, de conformidad con el principio de respeto de los derechos de defensa, que se notificará al condenado el recurso presentado por el Ministerio Público; Finalmente, el artículo 733-1 del Código antes mencionado establece que la decisión de la Corte criminal o el Tribunal de menores puede ser objeto de un recurso de apelación" (Traducción propia).

44 Di Manno (1997) p. 254-255. En este sentido ver también la Decisión No. 89-257 del 25 de julio de 1989, en el que se decide la constitucionalidad del artículo 29 de la LEY 315-15, en la que se le permite a las organizaciones sindicales iniciar acciones judiciales a favor de los empleados, donde la omisión persiste en tanto el trabajador parecería no contar con la libertad para establecer qué tipo de acción quisiera iniciar, cuál sería su pretensión y su interés. El Consejo agregó entonces que el trabajador debe especificar todos estos elementos y aquellos que garanticen su libertad individual, para conservar con ello la constitucionalidad de la disposición estudiada. 
ce en Francia la jurisdicción constitucional protectora de los derechos y libertades constitucionales. En efecto, el recurso de amparo que se instituyó en los ordenamientos jurídicos de Austria, Alemania, Italia, España y Bélgica, no se encontraba en la experiencia francesa ${ }^{45}$, sino hasta el 2008, cuando se estatuye la "Cuestión Prioritaria de Constitucionalidad".

Sin embargo, como se expuso en el título anterior, lo señalado no quiere decir que en Francia no hubiese un constitucionalismo ampliamente desarrollado. Las "reservas de interpretación" muestran un activismo judicial, que si bien moderado, garantía de la supremacía constitucional.

Con todo, antes de la reforma de 2008, los ciudadanos no podían elevar al Consejo Constitucional, a título individual, solicitudes cuando estimaren vulnerados sus derechos fundamentales. Esto no suponía la inexistencia de instrumentos jurídicos, incluso internacionales $^{46}$, dirigidos a la protección de los derechos constitucionales, pero sí evidencia que el Consejo Constitucional francés estaba diseñado para ejercer exclusivamente el control de constitucionalidad a priori y para conocer del contencioso electoral.

Las prolongadas y profundas críticas de la doctrina francesa al diseño de la jurisdicción constitucional demandaban el control a posteriori de las leyes; de allí que en 1990 y 1993 se haya propuesto la revisión de los artículos 61 y 63 de la Constitución, acompañada de una ley orgánica que estatuyera la "excepción de inconstitucionalidad" que incluía la legitimación de los ciudadanos para solicitar la inconstitucionalidad de las leyes. Dicha reforma se erigía sobre un sistema jurídico "esencialmente roto por el iceberg formado por el dogma de la soberanía de la ley, o por lo menos, del legislador" ${ }^{47}$. Con todo, por razones políticas y argumentos en contra del procedimiento planteado, la reforma fue abandonada. Ciertamente, se consideraba que el sistema instituido en 1958 permitía un proceso expedito, además de garantizar la seguridad jurídica basada en la revisión de constitucionalidad de la ley previamente a su aplicación, con iniciativa exclusiva en cabeza de las autoridades públicas $^{48}$.

Tras las dos tentativas de reforma constitucional en 1990 y en 1993 que no lograron realizarse, la ley constitucional $n^{\circ} 2008-724$ del 23 de julio de 2008, sobre la modernización de las instituciones de la V República, incorporó a la Constitución el artículo 61-1 y modificó el artículo 62 para crear un procedimiento de examen por vía de excepción de constitucionalidad de la ley ${ }^{49}$. Por lo anterior, la reforma del año 2008 que ahora se expondrá, se observa como una "verdadera revolución", en la medida en que Francia fue una de las pocas democracias europeas liberales que no permitían a sus tribunales la revisión posterior de los actos del Parlamento, inclusive cuando sus actos comprometieran los derechos constitucionales de los ciudadanos.

La QPC, no se trata propiamente de una Acción Pública que pueda ser iniciada por cualquier ciudadano, como se conoce en otras experiencias. Al contrario, se plantea como

45 Cappelleti (1990) p. 25.

46 Morand-Deviller (2009) p. 157-166. Como se resaltará más adelante, el control de convencionalidad hace parte del sistema transnacional de protección de derechos humanos en la práctica europea.

47 Cappelleti (1990) p. 25

48 Meindl (2003) p. 352-355

49 Alcoberro (2011) p. 19 
un incidente que se eleva ante las altas Cortes -Corte de Casación y Consejo de Estado-, para que sean estos tribunales los que concedan el recurso, siendo resuelto definitivamente por el Consejo Constitucional. Este diseño institucional se asemeja al establecido en el régimen alemán y austriaco ${ }^{50}$, donde el control constitucional a posteriori de las leyes se ha centralizado.

A pesar de que la reforma no establece un recurso individual directo ante el Consejo Constitucional, como la Verfassungsbeschwerde alemán, la introducción de un control a posteriori constitucional fortalece significativamente la protección de los derechos individuales a nivel nacional (BON Pierre, 2009). Francia, sin duda, ha sido pionera en la manera de instituir el control jurisdiccional de la administración pública, seguida por la Verwaltungsgerichtsbarkeit alemana y la giustizia amministrativa en Italia. No obstante, afirma Cappelleti, la misma existencia de una próspera y poderosa jurisdicción contenciosa administrativa demoró el desarrollo de la justicia constitucional en el Siglo $\mathrm{XX}^{51}$.

La reforma de 2008 establece que la QPC debe cumplir con varias condiciones, a saber, debe versar sobre una disposición legislativa, segundo, dicha regla debe amenazar derechos y libertades garantizados por la Constitución, tercero, se produce en el marco de un procedimiento pendiente de decisión ${ }^{52}$, entre otros aspectos formales, que serán tratados a continuación $n^{53}$.

El artículo 61-1 de la Constitución establece que el trámite de la QPC inicia cuando, en el curso de una controversia ante un tribunal judicial, se encuentre que una disposición legal es contraria a los derechos y libertades que la Constitución garantiza ${ }^{54}$, facultando a la parte en conflicto, para solicitar al juez la remisión al Consejo de Estado o a la Corte de Casación para que se estime la "seriedad y novedad" de la "cuestión constitucional”, y de considerarlo así, sea remitido al Consejo Constitucional. Así, el Conseil d'Etat y la Cour de cassation, son los únicos órganos constituidos que pueden elevar la QPC al Consejo Constitucional.

Cuando los jueces se enfrentan a una menor cuestión constitucional, es decir, a un compromiso menor de los principios de la Constitución, deben someter la cuestión a su

\footnotetext{
50 En la Constitución austríaca de 1920, modificada en 1929, se estableció que la inconstitucionalidad de una ley del Parlamento puede alegarse solo ante la Gerichtshof Obster (Supremo Tribunal Ordinario) o de la Verwaltungsgerichtshof (Tribunal Administrativo Supremo), ya que solo los tribunales podrían suspender en ese caso el procedimiento pendiente ante ellos y son ellos exclusivamente quienes pueden presentar ante el Verfassungsgerichthof (Tribunal Constitucional) el recurso, siempre que se dude de su constitucionalidad. Blanco (2005).

51 Cappelleti (1990) p. 164

52 BON (2009)

53 Fatin-Rouge (2009)

54 La amplitud de la lista de derechos y libertades constitucionales ha sido objeto de algunos debates doctrinarios. Sin embargo, en el amplio desarrollo que ha tenido el Consejo Constitucional, se han reconocido como tales, los principios fundamentales reconocidos por el constituyente de 1946, el preámbulo de la Carta de 1958, los derechos de libertad de asociación, derecho de la defensa y debido proceso, la libertad individual, la libertad de enseñanza, la libertad de conciencia, la independencia de la jurisdicción administrativa. No obstante, como se anotará más adelante, la extensión de derechos constitucionales integra a su vez, derechos contenidos en tratados internacionales, especialmente, del Convenio Europeo de Protección de los Derechos Humanos y las Libertades Fundamentales, que pueden ser aplicados directamente, por medio del control de convencionalidad. PINON (2010).
} 
superior jerárquico. Por ello, el Conseil d'Etat o la Cour de cassation tienen la obligación de comprobar la gravedad de la cuestión de manera oportuna, y solo cuando esta supera el requisito de "seriedad", es presentado ante el Consejo Constitucional ${ }^{55}$. La novedad no es idéntica a la seriedad y por ello, una QPC puede ser transmitida al Consejo Constitucional sin la necesidad de cuestionar su seriedad ${ }^{56}$.

Para autores como Disant, este mecanismo tiene varias ventajas, entre las que se señala la facultad del Conseil d'Etat y la Cour de cassation de participar en la elaboración de la jurisprudencia del Consejo Constitucional. Ciertamente, parecería garantizar los efectos beneficiosos de un diálogo directo entre los jueces y el Consejo Constitucional. En otras palabras, la QPC introducida por la reforma establece un “doble filtro", ejercido por el Consejo de Estado y la Corte de Casación ${ }^{57}$. La Sentencia 2009-595 del 3 de diciembre de 2009, que decidió la constitucionalidad de la Ley orgánica que reguló la QPC, dispuso que esta pueda ser aplicable a los procesos en curso. No obstante, tan solo serían admitidas las cuestiones presentadas a partir del 1 de marzo de 2010 mediante escrito motivado, debido a que en esa fecha entró en vigor la ley constitucional $n^{\circ} 2008-724$ del 23 de julio de $2008^{58}$

La ley orgánica del 9 diciembre de 2009 dispone en el artículo 23-1 la facultad de las partes en un litigio, para presentar ante el superior jerárquico, un escrito motivado en el que se exponga que una disposición legislativa vulnera los derechos y libertades garantizadas por la Constitución. Esta manera de activar la jurisdicción constitucional es rogada, debido a que el mismo artículo señala que el recurso no puede ser presentado de oficio.

Por supuesto, este filtro ha provocado algunas tensiones entre las altas Cortes, particularmente, como consecuencia de la "soberanía" que se le reconoce al Consejo de Estado y a la Corte de Casación, para la remisión de la cuestión de constitucionalidad, y las decisiones que puede tomar el Consejo Constitucional, que podrían alterar los criterios adoptados por las otras Cortes en la resolución de los asuntos propios de su jurisdicción ${ }^{59}$.

En particular, el Consejo de Estado y la Corte de Casación han optado, en algunas ocasiones, por no aplicar al litigio donde se ha resuelto la QPC, la decisión del Consejo Constitucional, si la declaración de inconstitucionalidad no tiene incidencia sobre la legalidad de la decisión objeto de la QPC. Con todo, el Consejo Constitucional ha construido una especie de "presunción de aplicabilidad" al litigio, debiendo aplicar el juez ordinario la condición de interpretación o la "reserva" considerada para tal caso ${ }^{60}$.

55 Disant (2010) p. 299

56 PIWNICA (2011)

57 Disant (2010) p. 299. Señala el autor que en el marco de los fallos del 8 de febrero de 2007 (Société Arcelor et Lorrainte et autres), y el arrêt Larrouturu del 1 de septiembre de 2000, se produce ya un "diálogo entre jueces", arbitrado ahora por la función del Consejo Constitucional, quien media, de forma general, entre la interpretación constitucional y la creación del derecho administrativo y privado.

58 Bulletin Officiel du Ministère de la Justice et des Libertés n 2010-02 du 30 avril 2010, Circulaire SG/ SADJPV du 1er mars 2010 relative à la présentation du principe de continuité de l'aide juridictionnelle en cas d'examen de la question prioritaire de constitutionnalité par le Conseil d'Etat, la Cour de cassation et le Conseil constitutionnel NOR : JUSA1005991C

59 DisAnt (2011) p. 189.

60 Disant (2011) p. 192. 
Esta fricción entre las Cortes produjo que durante la fase inicial de aplicación del mecanismo de revisión de la Constitución, las remisiones al Consejo Constitucional sean relativamente bajas. En efecto, solo un cuarto de las cuestiones (QPC) presentadas a la Corte de Casación y el Consejo de Estado fueron remitidos al Consejo Constitucional ${ }^{61}$.

El artículo 23-1 de la Ley orgánica exige también que en el proceso de constitucionalidad intervenga el Ministerio Público. En aquellos procesos en los que no haga parte el Ministerio, la decisión le debe ser comunicada para que presente su concepto sobre la constitucionalidad de la norma. Esto no significa que el Ministerio se haga parte dentro del trámite en cuestión, pues el litigio se resolverá de acuerdo a lo establecido para cada jurisdicción, pero intervendrá en el ejercicio del control de constitucionalidad ${ }^{62}$.

De igual modo, el Presidente de la República, el Primer Ministro, los presidentes de la asamblea nacional o del senado son "llamados" al proceso, para presentar sus "observaciones" como altas autoridades políticas. Este requisito contenido en la ley orgánica ha sido criticado y cuestionado en la medida en que puede significar una extensión y dilación innecesaria del proceso. Con todo, se ha justificado debido a que el control de la ley por medio de la QPC opone su poder sobre una norma votada, promulgada y aplicada, y que, aunque imperfecta, se "ha beneficiado de la legitimidad que da el tiempo, siendo las observaciones una manera de reforzar la legitimidad que se ve comprometida con la decisión de constitucionalidad"63.

Como se mencionó, para la presentación del recurso se exige un escrito distinto y motivado. El Consejo Constitucional interpretó que el legislador orgánico ha pretendido facilitar el tratamiento de la QPC y permitir que la jurisdicción a la que se someta pueda juzgar la solicitud de la cuestión, cuanto antes, para no retardar el procedimiento ${ }^{64}$. En el artículo 23-2, la ley orgánica dispone que la jurisdicción correspondiente deba resolver, mediante una resolución motivada, la transmisión de la QPC al Consejo de Estado o a la Corte de Casación.

Por lo anterior, el filtro jurisdiccional creado con la QPC también tiene por misión, prevenir que la QPC sea convertida en una estrategia dilatoria del proceso y evitar un litigio artificial; en segundo lugar, impedir la elusión del sistema legal, es decir, evitar que la QPC sea invocada en los tribunales ordinarios con el propósito de provocar el incumplimiento de una norma legislativa que contenga el marco estricto de legalidad ${ }^{65}$.

En el artículo 23-2 citado se establece que la QPC debe resolverse con "prioridad". Esto quiere decir que el juez debe resolver la cuestión preferentemente a los demás procesos en curso, y transmitirla al Consejo de Estado o a la Corte de Casación en un plazo de ocho días a partir de su pronunciamiento, remitiendo el recurso y las alegaciones de las partes. Esta decisión no tiene ningún recurso, y aquella que rechace la solicitud puede ser revisada

\footnotetext{
61 Flores (2014) p. 308.

2 Lizop (2010) p. 12

Lizop (2010) p. 12

64 Decisión no 2009-595 (2009)

65 Flores (2014) p. 309.
} 
solo con el recurso que sobre la sentencia se proponga, se trate de una apelación o reposición.

El artículo 23-2 de la ley orgánica y el último párrafo del artículo 62 de la Constitución dispone también, que: "Contra las resoluciones del Consejo Constitucional no cabrá recurso alguno. Se impondrán a todos los poderes públicos y a todas las autoridades administrativas y jurisdiccionales".

La QPC, según lo dispuesto por el artículo 23-3, una vez concedida, suspende el proceso en el cual se planteó, hasta la recepción de la resolución del Consejo de Estado o de la Corte de Casación o del Consejo Constitucional, si la cuestión es sometida a su conocimiento. Empero, el proceso no se suspende si la persona está privada de la libertad o cuando la instancia tenga como objeto poner término a esta medida.

El artículo citado trae consigo otra excepción avalada constitucionalmente por el Consejo Constitucional en la decisión del 3 de diciembre de 2009. Cuando la suspensión del proceso provoca un peligro de traer consigo consecuencias irremediables para los derechos de las partes o perjuicios claramente excesivos, la jurisdicción que decida transmitir la QPC al Consejo podrá decidir los puntos que deban ser resueltos inmediatamente. Esto supone que excepcionalmente, la jurisdicción que eleva la QPC puede decidir los puntos que puedan generar un perjuicio irremediable para las partes dentro del proceso.

El artículo 23-4 de la Ley orgánica establece un plazo de tres meses a partir de la recepción de la solicitud prevista en el artículo 23-2 o en el último párrafo del artículo 23-1, para que el Consejo de Estado o la Corte de Casación se pronuncien sobre la remisión de la QPC al Consejo Constitucional. Este reenvío se concede siempre y cuando se cumplan las condiciones ya mencionadas, previstas en los numerales $1^{\circ}$ y $2^{\circ}$ del artículo $23-2$ y que la cuestión sea "nueva y revista un carácter serio". El artículo 23-5 dispone también que la causa fundada en una disposición legislativa puede ser planteada incluso por primera vez en casación, con motivo de una instancia ante el Consejo de Estado o la Corte de Casación; en este caso, la resolución de la cuestión también debe resolverse de manera preferente y suspende el proceso hasta tanto el Consejo Constitucional resuelva la QPC.

El primer párrafo del artículo 23-4 y el tercer párrafo del artículo 23-5 prevén que la QPC solo puede ser sometida al Consejo Constitucional, si "la cuestión es nueva”. Este criterio se refiere a que el Consejo Constitucional todavía "no haya tenido ocasión de aplicar" la norma objeto de estudio. Por consiguiente, opina el Consejo Constitucional, una QPC no puede ser nueva por el único motivo de que la disposición legislativa impugnada no haya sido examinada previa y explícitamente por el Consejo. En el marco de la sentencia expuesta, el requisito de "novedad" supone la inexistencia no solo de vacios normativos, sino también jurisprudenciales.

La "jurisprudencia” como referente normativo, ha generado algunas controversias, en la medida en que su tratamiento es difícil, debido a su ambivalencia: a veces, se puede establecer como condición de fondo del recurso presentado contra un texto cuya claridad o sentido jurídico ha sido definido por un precedente, pero a veces, por el contrario, la jurisprudencia justifica la decisión de no remisión de la QPC por razones formales, pues la va- 
guedad o ambigüedad de la legislación ha encontrado un pronunciamiento jurisprudencial previo $^{66}$.

Inclusive, el Consejo Constitucional ha señalado que, aun cuando en el caso particular exista una decisión de constitucionalidad a priori que haya declarado la norma conforme a la Constitución, el Consejo puede volver a estudiar la constitucionalidad de la disposición, si en el caso particular existen motivos que no fueron objeto de su decisión y que por consiguiente, no fueron objeto del control previo ${ }^{67}$.

En otras palabras, la "cuestión novedosa", estimó el Consejo, no se aprecia con respecto a la disposición legislativa impugnada, pues en este caso, cualquier cuestión que todavía no haya sido examinada por el Consejo Constitucional siempre sería novedosa. Por ello, la QPC permite a la jurisdicción ordinaria o contencioso administrativa interpretar y extraer de precedentes del Consejo Constitucional, decisiones previas que permitan calificarla de "novedosa". De este modo este criterio de la novedad habilita al Consejo de Estado y a la Corte de Casación para apreciar el interés de recurrir al Consejo Constitucional.

No obstante, lo señalado no implica que el Consejo Constitucional haya acogido un sistema de precedentes vinculantes fuerte. Por el contrario, el mismo Consejo Constitucional ha señalado que la "autoridad de la cosa interpretada" es vinculante para todos los poderes públicos, pero esta no le puede ser oponible de la misma manera, en la medida en que el Consejo es libre de modificar su jurisprudencia ${ }^{68}$.

Es por lo anterior que el Consejo de Estado y la Corte de Casación han hecho uso de la "seriedad" de la cuestión, y en muy pocas ocasiones se han referido a su novedad. En efecto, desde la entrada de vigencia de la reforma hasta enero del 2014, solo se enviaron 24 asuntos al Consejo Constitucional, basado en el criterio de "novedad". Los demás asuntos se basaron en el criterio de seriedad, que se ha interpretado como asuntos que muy probablemente desemboquen en la declaratoria de inconstitucionalidad de la ley ${ }^{69}$.

La "seriedad" combina en realidad dos criterios, igualmente ambivalentes: en primer lugar, el Consejo de Estado y la Corte de Casación no pueden sustituir el Consejo Constitucional para resolver la validez formal o material de la ley, y por ello, se considera la posibilidad o necesidad de una "reserva de interpretación" sobre el contenido normativo de la ley; en segundo lugar, se considera el compromiso a derechos o valores constitucionales, que podrían ser limitados de una manera manifiestamente desproporcionada por virtud de la norma cuestionada ${ }^{70}$.

La QPC, vista así, abre en realidad un nuevo proceso, distinto de la demanda principal, indiferente a la decisión de fondo sobre el asunto concreto. En este sentido, la QPC no puede referirse al objeto principal de la instancia. La ordenanza orgánica del 7 de noviembre de 1958 confirma esta calificación ${ }^{71}$.

66 FLORES (2014) p. 312

67 DisANT (2011) p. 203.

${ }_{68}$ Disant (2010) p. 531. Cita como ejemplo la decisión del Consejo Constitucional No. 99-410 del 15 de marzo de 1999.

69 BARQue (2014) p. 355

70 FLORES (2014) p. 314.

71 LÉvy (2010) p. 18 
La sentencia del Consejo Constitucional del 3 de diciembre de 2009 gana especial relevancia debido a las "reservas" que planteó respecto a la constitucionalidad de las normas orgánicas de la QPC. En primer lugar, interpretó el Consejo, el recurso no priva al accionante de la facultad de iniciar un nuevo procedimiento que pudiese tener en cuenta la resolución del Consejo Constitucional; segundo, se estableció que las disposiciones de los artículos 23-3 a 23-7 se deben aplicar garantizando el respeto de un procedimiento justo y equitativo ante el Consejo de Estado y la Corte de Casación ${ }^{72}$. Esta reforma tiene un triple objetivo, sostiene el Consejo Constitucional: a. dar un nuevo derecho a las partes dentro del proceso que les permita invocar los derechos constitucionales, b. purgar el ordenamiento jurídico de disposiciones inconstitucionales, c. garantizar la preeminencia de la Constitución en el orden interno ${ }^{73}$.

De esta manera, el Consejo Constitucional se convierte en el gran ganador de la reforma que instaura la QPC. El Consejo ve reforzadas sus competencias debido a que solo él tiene legitimidad para sancionar la inconstitucionalidad de la ley; asume el rol de intérprete de la Constitución y emite sentencias con efectos generales o erga omnes. Esta función se aproxima al writ of certiorari américano, que facultaría al Consejo para elegir el campo de sus intervenciones, por medio del amplio poder que le otorga la misma Constitución, al darle la potestad de determinar la novedad de la cuestión ${ }^{74}$.

En tercer lugar, establece el Consejo Constitucional la reserva del "cambio de circunstancias" de derecho o de hecho, que afecten el alcance de la disposición legislativa criticada, pero que había sido juzgada con antelación. Esta reserva, precisó el Consejo, le da competencia para revisar la constitucionalidad de una norma cuya constitucionalidad ya había sido estudiada con anterioridad, pero que debido al "cambio en las normas constitucionales o cambio en las circunstancias, de derecho o de hecho", puede revisarse nuevamente en la medida en que tales circunstancias afectan el "alcance de la disposición legislativa cuestionada”. Precisa el autor Pierre-Yves Gahdoun, los cambios de circunstancias en derecho deben ser comprendidos ampliamente, y son relativos a los elementos jurídicos en torno a los cuales debe referirse el Consejo Constitucional, siendo concerniente a dos situaciones: A. La modificación de la Constitución, de la ley o de la jurisprudencia. B. La trasformación de la ley y de la Constitución no ofrecen mayor debate en la medida en que suponen que la disposición objeto de control ha sido modificada ${ }^{75}$.

\footnotetext{
72 LÉvy (2010) p. 18

73 Ver Consejo Constitucional, Decisión n 2009-595 DC (2009). Expuso el Consejo Constitucional: "La referencia a una declaración de conformidad con la Constitución «en los fundamentos y el fallo» responde a la evolución de los métodos aplicados por el Consejo Constitucional desde 1959 en la redacción de sus sentencias sobre leyes ordinarias. El hecho de exigir, para que se oponga a una QPC [Cuestión prioritaria de constitucionalidad] que la disposición ya haya sido declarada conforme a la Constitución por el Consejo Constitucional, que este último haya procedido a una tal declaración de conformidad «en los fundamentos y el fallo» de su resolución, tiene como consecuencia dispensar las jurisdicciones de tener en cuenta esta evolución de los métodos, precisando que, en principio, cuando el Consejo Constitucional desestima en los motivos una queja invocada contra una disposición legislativa, la declara conforme a la Constitución en su integridad”.

74 BARQUe (2014) p. 355

75 Gahdoun (2010) p. 88. La modificación de la constitución supone que, en la dinámica de los sistemas jurídicos, puede suceder que una norma N1, que en un tiempo t1, era compatible con la Constitución, en
} 
En otras palabras, el Consejo ha reconocido que la inconstitucionalidad sobrevenida se puede predicar tanto de la modificación de la Constitución, como de la jurisprudencia. Esto supone que la modificación de un criterio jurisprudencial, puede alterar la validez material de una disposición cuya constitucionalidad ya había sido decidida, dando al traste con la seguridad jurídica de la cosa juzgada constitucional.

Esta posición del Consejo Constitucional ha sido criticada en la medida en que se reconoce como un signo de erosión de la autoridad de la regla jurisprudencial. La posibilidad de revivir interrogantes sobre el alcance o la interpretación de la Constitución, sobre la autoridad de las decisiones del Consejo y sus métodos, reduce inclusive, la estabilidad de la Constitución, pues la evolución de la jurisprudencia del Consejo constitucional provoca una correlativa dificultad en la capacidad de los actores para identificar las decisiones constitucionales precedentes, su coherencia y la fuerza vinculante que pudiese preservar la autoridad de la jurisprudencia constitucional ${ }^{76}$.

El cambio de circunstancias también incluye el cambio o transformación de la "jurisprudencia constante" 77 . Esto supone, en otras palabras, que la variación del criterio jurisprudencial del Consejo de Estado o de la Corte de Casación, pueden dar lugar al cambio de circunstancias que puede relativizar el poder vinculante de la jurisprudencia constitucio$\mathrm{nal}^{78}$. De igual manera, cuando la ley se refiere al cambio de circunstancias de hecho, opina el autor citado, el Consejo Constitucional no debe hacer consideraciones fácticas relativas al asunto en estudio, en la medida en que las mismas comprometerían la competencia de los jueces especializados, quienes definen el asunto concreto de fondo. Al contrario, este cambio de circunstancias supone una revisión de la "situación general organizada por el texto legislativo cuestionado”. Esto se explica porque la anulación eventual de la ley por el Consejo tendría efectos erga omnes, y no supone un juicio del asunto en conflicto ${ }^{79}$.

un tiempo $\mathrm{t} 2$, se vuelva incompatible con ella, produciéndose la inconstitucionalidad sobreviniente. Esta incompatibilidad, aclara Orunesu, puede deberse a la modificación de una norma en el nivel constitucional, sea por una formulación normativa novedosa, o sea por una interpretación que se atribuía a formulaciones normativas existentes. Este caso se produce cuando, sin producir cambio en el texto constitucional, se altera el significado atribuido a alguna de sus formulaciones normativas. ORUNESU (2012) p. 135.

76 Disant (2011) p. 218.

77 La "jurisprudencia constante", se entiende como la reiteración prolongada en el tiempo, de una determinada solución interpretativa por parte de varios tribunales. Usualmente, son los jueces de inferior jerarquía, quienes se rigen por la jurisprudencia constante, tanto de sus superiores jerárquicos como de las altas cortes. PERROT (2010), p. 29. Cita la sentencia del 3 de noviembre de 1955 de la Corte de Casación, Asuntos criminal. D. 1956-557.

78 La Corte Europea de Derechos del Hombre ha sido quizá el órgano supranacional que ha extendido con mayor fuerza el poder vinculante del precedente en todos los países de la Unión Europea, entre ellos por supuesto Francia. Diferenciando entre un criterio orgánico y uno material, la Corte Europea ha entendido que materialmente la jurisprudencia hace parte de una visión extensiva de qué puede entenderse por "ley", dentro de la cual se encuentran las "reglas jurisprudenciales" de carácter escrito, señalando la Corte que "la ley es el texto en vigor que las jurisdicciones internas competentes han interpretado", leyendo cualquier texto normativo a la luz de la interpretación que la jurisdicción le ha brindado. Disant (2010) p. 230 y 231. Cita Decisión de la CEDH del 15 de noviembre de 1996, CANTONI Vs. FRANCIA, No. 17862/91 y Recomendación de la CEDH del 10 de octubre de 2006, PRESSINO VS. FRANCIA No. 40403/02.

79 Gahdoun (2010) p. 90. Para explicar este punto, el autor señala como ejemplo la Decisión del 10 de junio de 2009 del Consejo Constitucional No. 2009-580, donde se entiende que la implementación de nuevas 
Ahora bien, hasta este punto hemos demostrado la existencia de las condiciones necesarias para la procedencia de la QPC. Esta coincide -y redunda hasta cierto punto- con los remedios supranacionales que se han concedido a los ciudadanos franceses, que inclusive, puede llegar en última instancia, ante el Tribunal Europeo de Derechos Humanos ${ }^{80}$. En efecto, el control de convencionalidad faculta al juez de la causa, para (in)aplicar la ley, sin necesidad de acudir al Consejo Constitucional. En otras palabras, la coexistencia de la QPC con el control de convencionalidad facilita al ciudadano una estrategia legal: Por un lado, puede decidir plantear la QPC, y esperar con ello la decisión de inconstitucionalidad de la norma. Pero, en segundo lugar, el solicitante puede dejar de utilizar la QPC, para solicitar el control de convencionalidad, y en este caso, el solicitante va a confiar la jurisprudencia del Tribunal Europeo de Derechos Humanos. El artículo 61-1 de la ley orgánica de la QPC respeta esta elección y no transforma la cuestión de constitucionalidad en un trámite forzoso o de aplicación automática ${ }^{81}$.

Así, el aparente conflicto entre QPC y el control de convencionalidad se resuelve mediante una combinación: impugnar la validez de la disposición legal en virtud de un convenio internacional por medio de la QPC no está prohibido. Los dos temas son independientes y autónomos. Por otra parte, se puede recurrir al Tribunal Europeo de Derechos Humanos para cuestionar la validez de una ley en virtud de la Convención Europea de Derechos Humanos, mientras que esto no haya sido un resuelto por la QPC ${ }^{82}$. Finalmente, el conflicto, en el caso francés, se resolvería por medio del bloque de constitucionalidad ${ }^{83}$.

Por este motivo, se considera, la QPC podría replegarse, en la medida en que solo tendría sentido si el nivel de protección que otorga la Constitución francesa es mayor respecto del que otorgan los convenios o tratados internacionales. Por el contrario, si la protección otorgada por el convenio, integrado al bloque de constitucionalidad, es superior, la mejor solución sería el control de convencionalidad ${ }^{84}$.

Otras voces opinan que la QPC y el control de convencionalidad no tienen por qué colisionar, en la medida en que no responden a las mismas necesidades. Por una parte, la QPC protege derechos y libertades constitucionales, mientras que el control de convencionalidad se encuentra abierto a proteger cualquier derecho que se encuentre en un tratado internacional de aplicación directa. Sin embargo, cuando el control versa sobre una disposición contraria a la Constitución y una directiva comunitaria, el juez debería decidir inicial-

tecnologías, en especial, el uso del espectro electromagnético, supone para el ordenamiento jurídico una necesidad de adaptación del derecho a la libertad de comunicaciones, que en sí mismo, se demanda de toda la circunstancia fáctica que rodea la aplicación y efectividad de la norma.

80 Disant (1999) p. 230 y 231. Cita Decisión de la CEDH del 15 de noviembre de 1996, Cantoni vs. Francia, No. 17862/91 y Recomendación de la CEDH del 10 de octubre de 2006, Pressino Vs. Francia No. 40403/02.

81 Guillaume (2010)

82 PIWNiCA (2011)

83 El bloque de constitucionalidad francés ha sido descrito como el reconocimiento de un valor supralegal de tratados internacionales sobre derechos humanos, que en algunos casos, adquieren valor constitucional. El Consejo Constitucional ha interpretado que no se espera que los tratados internacionales adquieran un rango constitucional, sino que las normas convencionales se interpretan como disposiciones de referencia de la constitucionalidad, esto es, "normas de referencia aplicables". BRUCE (2005). P. 540.

84 Alcoberro (2011) p. 44 
mente sobre el terreno de la convencionalidad, salvo si el objeto del litigio comprometiera una regla o principio inherente a la identidad constitucional ${ }^{85}$.

Esta discusión ha conducido a abordar el control de convencionalidad en tres sentidos: como sistema concurrente con el derecho constitucional interno, como sistema que se ha confundido con el ordenamiento jurídico interno francés, o como fuente de derecho internacional que complementa el derecho constitucional interno ${ }^{86}$. Esta tensión se ha resuelto de muchas maneras, entre otras, bajo el entendido de una desconexión entre el control de constitucionalidad (QPC) y el control de convencionalidad, entendiendo el problema, como un asunto de competencia, más allá que un asunto de contenido, pues los asuntos que se presentan al juez de convencionalidad también definirán el derecho sustantivo que resolverá dicha tensión; la segunda forma en que se ha resuelto ha sido reconociendo la superioridad de la norma internacional sobre la constitucional, lo que resulta en todo caso problemático, en la medida en que le resta supremacía a la Carta. En todo caso, el asunto del control de convencionalidad ha extrañado y sugerido intensas discusiones y variadas soluciones que abogan por una necesaria conciliación y unificación entre el derecho europeo y la constitución francesa ${ }^{87}$.

Lo señalado supone entonces que la QPC propicia el diálogo entre los tribunales, Corte de Casación y Consejo de Estado, así como con el juez de convencionalidad. Obviamente, esto no excluye los conflictos entre la jurisprudencia ni posturas contradictorias, pero en la mayoría de los casos, logran articularse de formas razonables y apropiadas. Estas conexiones siempre requieren maduración ${ }^{88}$.

La QPC es, sin duda, una fuente de importante actividad judicial -aunque no la única, como se demostró en el título anterior- y ha aportado importantes decisiones en la experiencia comparada. Precisamente, en la medida en que la Declaración de 1789 y demás "principios" han sido integrados al ordenamiento jurídico constitucional francés, y los mismos sirven de fuente para la solución de controversias particulares, la práctica gala ha experimentado una profundización significativa en su control constitucional. El Consejo Constitucional, en ejercicio de la QPC, se ha pronunciado en diversas y complejas materias, entre otras, se ha referido a la libertad de matrimonio relativa a los artículos $2^{\circ}$ a $4^{\circ}$ de la Declaración de $1789^{89}$, la libertad de empresa ${ }^{90}$, la igualdad de acceso a los cargos públicos ${ }^{91}$, el derecho a la tutela judicial efectiva de acuerdo al artículo 16 de la Declaración de $1789^{92}$, la protección de derechos adquiridos ${ }^{93}$, el derecho a recibir una indemnización

85 BON (2009) p. 209

86 Akandji-Kombé (2014) p. 301.

87 AKandji-Kombé (2014) p. 302.

88 Akandji-Kombé (2014) p. 307.

89 2010-92 QPC (2011)

90 2010-89 QPC (2011)

91 2010-94 QPC (2011)

92 2010-90 QPC (2011)

93 2010-102 QPC (2011) 
apropiada en caso de expropiación ${ }^{94}$, el derecho de propiedad ${ }^{95}$, el derecho al trabajo ${ }^{96}$, el derecho al medio ambiente ${ }^{97}$, y el principio de participación de los trabajadores en la determinación colectiva de las condiciones de trabajo ${ }^{98}$, entre otros. Como se puede observar, la experiencia francesa, a partir de la QPC, abandona un diseño institucional que parecería haber contado con un sistema de control de constitucionalidad singular. No obstante, el Consejo Constitucional había sido portador de importantes instituciones como el "bloque de constitucionalidad" y las "reservas" como mecanismo de modulación de sentencias y activismo judicial, que supondría más similitudes que diferencias con la experiencia alemana, italiana o española. Sin embargo, la QPC se ha convertido en un dispositivo que ha incentivado exponencialmente el control de constitucionalidad y que se ha convertido en una importante fuente de sentencias, que dada su amplia protección de derechos fundamentales y constitucionales, compiten incluso con el control de convencionalidad, como se explicó en líneas anteriores.

\section{CONCLUSIÓN}

Como se ha constatado en este documento, la QPC y las "reservas" se muestran como un recurso y una herramienta poderosa de control de las decisiones de las mayorías parlamentarias. Por supuesto, la sentencia del 3 de diciembre de 2009 del Consejo Constitucional nos da los elementos preliminares para apreciar el despliegue de un poder y una doctrina constitucional significativa, y que entrará a reñir con las competencias de las jurisdicciones administrativas y ordinarias para hacer respetar la supremacía del derecho internacional y del derecho de la Unión Europea.

Con todo, se ha expuesto una crítica a la manera en que se ha considerado en algunos estudios, que la experiencia francesa es la excepción al constitucionalismo europeo. Al contrario, el uso de las reservas, revela que desde 1958, Francia se vio influenciada por la corriente de pensamiento dominante en la región. Empero, la QPC se muestra como una herramienta más expedita de trasformaciones constitucionales, en la medida en que abrió la legitimación para cuestionar la constitucionalidad de las leyes.

Ciertamente, las condiciones de "novedad" y "seriedad" suponen un amplio poder discrecional de la jurisdicción constitucional. En efecto, en la decisión de 2009 se expone que el criterio de "presentar un carácter serio", es en este caso ligeramente más exigente, y supone una "duda elevada por una mente iluminada". Con seguridad, la participación de las demás jurisdicciones, apunta el Consejo Constitucional, le permitirá al Consejo de Estado y la Corte de Casación desempeñar un importante "filtro" en la selección de los asuntos de relevancia jurídica y constitucional.

\footnotetext{
94 2010-87 QPC (2011)

95 2010-96 QPC (2011)

96 2010-98 QPC (2011)

97 2013-346 QPC (2013)

98 2010-91 QPC (2011)
} 
Junto al control de convencionalidad, la QPC aproximará a la jurisdicción constitucional al "gobierno de los jueces", aunque limitado, pero que ha relativizando en buena medida, la singularidad del constitucionalismo galo.

\section{BIBLIOGRAFÍA}

Alcoberro Llivina, Karina (2011): "La cuestión prioritaria de constitucionalidad: ¿el fin de la excepción francesa?” Revista Vasca de Administración Pública, No. 90, mayo-agosto: pp. 17-65.

AKANDJI-Kombe, Jean-François (2014): "Droit constitutionnel, droit international et droit européen des droits de l'homme: concurrence, confusion, complémentarité?", Revue Droit Social, vol 1, No. 4, Apr 2014: pp. 419-432.

BARQue, François (2014): "La question nouvelle dans la procédure de la question prioritaire de constitutionnalité. Une critère discret aux effets considérables sur le contentieux constitutionnel", en Revue Française de Droit Administratif, 30e année, No. 2 Mars Avril: pp. 54-75.

Blanco VAldÉs, Roberto (2005): El Estado social y el derecho político de los norteamericanos, en Modelos constitucionales en la historia comparada (Oviedo, Ed. Universidad de Oviedo).

Bon, Pierre (2009): "La cuestión prejudicial de constitucionalidad en Francia ‘solución o problema?", Teoría y Realidad Constitucional, No. 23. (Traducción de M. J. de las Heras y F. Reviriego): pp. 313-325.

BRUCE, Eva (2005): "Faut-il intégrer le droit communautaire aux normes de référence du contrôle de constitutionnalité ?", Revue française de droit constitutionnel, No. 63: pp. 539-560

Cappelleti, Mauro (1990): Le pouvoir des juges, (Traduction par René David). Presses (París, Ed. Universitaires d aix-Marseille).

DÁvila S, Carlos Mario (2013): "Los cambios constitucionales de 1971 en Francia y de 1991 en Colombia. Un análisis desde el punto de vista de la Teoría de la Revolución Jurídica", Vniversitas, No. 126: pp. 123-163

Di Manno, Thierry (2001): Le juge constitutionnel et la tecnhique des décisions "interprétatives" en France et en Italie (París, Presses Universitaires d'aux-marseille).

Disant, Mathieu (2010): L'autorité de la chose interprétée par le Conseil Constitutionnel, (Paris, Bibliothèque Constitutionnelle et de Science politique, L.G.D.J., l'extenso éditions).

Disant, Mathieu (2011): Droit de la Question Prioritaire de constitutionnalité, Cadre juridique pratiques jurisprudentielles (París, Ed. Lamy).

Escobar, Lina Marcela (2005): La modulación de sentencias y el poder normativo del juez de constitucionalidad colombiano. Monografía sin publicar. Tesis presentada para optar al título de Doctor en Derecho (Universidad del País Vasco/Euskal Herriko Unibertsitatea). 
Fatin-Rouge, Stéfanin (2009): "Le Conseil Constitutionnel dans la révision constitutionnelle du 23 juillet 2008 sur la modernisation des institutions”, Revue française de droit constitutionnel, No fuera de serie: pp. 269-290.

Flores, Philippe (2014): "La chambre sociale et la question prioritaire de constitutionnalité: de la distorsion entre l'image doctrinale et la réalité juridictionnelle” Droit Social, vol 1, No 4, Apr 2014: pp. 308-316.

Gahdoun, Pierre-Yves (2010): "Argumenter la question prioritaire de constitutionnalité", en: Rousseau Dominique (Edit.) La question prioritaire de constitutionnalité, (Paris, lextenso éditions LGDJ) pp. 255-290.

Ginsburg, Tom (2006): Judicial Review in New Democracies, Constitutional courts in asian cases (Cambride, Cambride University Press).

Guillaume, Marc (2010): "La question prioritaire de constitutionnalité", Disponible en: http://www.conseil-constitutionnel.fr/conseil-constitutionnel/root/bank_mm/QPC/ qpc_mguillaume_19fev2010.pdf Fecha de consulta: 01 de junio de 2014.

Hernández Valle, Rubén (1994): "La tipología de las sentencias constitucionales con efectos fiscales", Revista Española de Derecho Constitucional, Año 14. Núm. 41. Mayoagosto: pp. 225-245.

LÉvY, David (2010): “Devant qui soulever la question prioritaire de constitutionnalité?”, en RoussEau, Dominique (Edit.) La question prioritaire de constitutionnalité (Paris, lextenso éditions LGDJ): pp. 21-42.

Lizop, Arnaud (2010): "Qui peut soulever la question priotitaire de constitutionnalité?", en: Rousseau, Dominique (Edit.) La question prioritaire de constitutionnalité (Paris, lextenso éditions LGDJ) pp. 11-21.

MeIndL, Thomas (2003): La notion de droit fundamental dans les jurisprudences et doctrines constitutionnelles francaises et allemandes (París, Ed. Bibliothèque Constitutionnelle et de Science Politique, Librairie Gènèrale de Droit et de Jurisprudence).

Meny, Yves (1986): "El Proceso Legislativo en Francia” (Trad. Helena Moya) Revista Española de Derecho Constitucional, Año 6. № 16. Enero-abril: pp. 237-276

Morand-Deviller, Jacqueline (2009): "El control de convencionalidad y de constitucionalidad por el juez administrativo francés", Revista de Derecho, Universidad de San Sebastián, No 13: pp. 157-166.

Orunesu, Claudina (2012): Positivismo jurídico y sistemas constitucionales (Madrid, Ed. Marcial Pons).

Perrot, Roger (2010) Institutions judiciaires (París, Ed. Montchrestien l'extenso èditions).

Pinon, Stéphane (2010); "Sistema constitucional de Francia”, Revista de Derecho Constitucional Europeo, Año 7. No 14. julio-diciembre : pp. 17-74

PIWNICA, Emmanuel (2011): "L'appropriation de la question prioritaire de constitutionnalité par ses acteurs", Pouvoirs 2 № 137: pp. 169-181

Rousseau, Dominique (2010): La question prioritaire de constitutionnalité, (París, Ed. Lextenso).

Sarmiento Erazo, Juan Pablo (2012): "La modulación de sentencias como medio para articular la oportunidad política de la Corte Constitucional colombiana. El caso de las parejas del mismo sexo", Revista de Derecho, No 37, enero-junio: pp. 283-320. 
Sarmiento Erazo, Juan Pablo (2010): "Sentencias de la Corte Constitucional con efectos reparativos, entre el Juez Administrativo y el Juez Constitucional”, Revista Vniversitas, No 121, julio-diciembre: pp. 161-192.

Sieder. Rachel; Schjolden, Line y Angell, Alan (2005): The Judicialization of Politics in Latin America (Manchester, Ed. Palgrave MacMillan).

VIALA, Alexandre (1999): Les réserves d interprétation dans la jurisprudence du conseil constitutionnel (París, Bibliothèque constitutionnelle et de science politique, LG.D.J.)

\section{JURISPRUDENCIA CITADA}

Francia, Consejo Constitucional, Decisión 82-142 (1982)

Francia, Consejo Constitucional, Decisión No. 84-172 (1984)

Francia, Consejo Constitucional, Decisión No. 93-329 (1994)

Francia, Consejo Constitucional, Decisión n 2009-595 DC (2009)

Francia, Cuestión Prioritaria de Constitucionalidad 2010-89 QPC (2011), Journal officiel du 22 janvier 2011, p. 1387, texte $\mathrm{n}^{\circ}$ 66, cons. 3

Francia, Cuestión Prioritaria de Constitucionalidad 2010-94 QPC (2011), Journal officiel du 29 janvier 2011, p. 1896, texte $\mathrm{n}^{\circ} 0$, cons. 3

Francia, Cuestión Prioritaria de Constitucionalidad 2010-92 QPC (2011), Journal officiel du 29 janvier 2011, p. 1894 , texte $n^{\circ} 82$, cons. 4 et 7.

Francia, Cuestión Prioritaria de Constitucionalidad, 2010-90 QPC (2011), Journal officiel du 22 janvier 2011, p. 1387, texte ${ }^{\circ}$ 67, cons. 7

Francia, Cuestión Prioritaria de Constitucionalidad, 2010-102 QPC (2011), Journal officiel du 12 février 2011, p. 2759, texte $n^{\circ} 53$, cons. 3 et 4

Francia, Cuestión Prioritaria de Constitucionalidad, 2010-87 QPC (2011), Journal officiel du 22 janvier 2011, p. 1384, texte $\mathrm{n}^{\circ}$ 64, cons. 3

Francia, Cuestión Prioritaria de Constitucionalidad, 2010-96 QPC (2011), Journal officiel du 5 février 2011, p. 2354, texte ${ }^{\circ} 88$, cons. 5

Francia, Cuestión Prioritaria de Constitucionalidad, 2010-98 QPC (2011), Journal officiel du 5 février 2011, p. 2355, texte $n^{\circ} 90$, cons. 3

Francia, Cuestión Prioritaria de Constitucionalidad, 2013-346 QPC (2013) - Sociedad Schuepbach Energy LLC

Francia, Cuestión Prioritaria de Constitucionalidad, 2010-91 QPC (2011), Journal officiel du 29 janvier 2011, p. 1894, texte $\mathrm{n}^{\circ} 81$, cons. 3 